\title{
Barreira capilar construída com resíduo pré-tratado mecânica e biologicamente
}

\section{Capillary barrier constructed with mechanical biological treatment waste}

\author{
Ronaldo Luis dos Santos Izzo \\ D.Sc. pelo Instituto Alberto Luiz Coimbra de Pós-graduação e Pesquisa de Engenharia (COPPE) da Universidade Federal do Rio de Janeiro (UFRJ) - \\ Rio de Janeiro (RJ), Brasil. Professor de Engenharia Geotécnica da Universidade Tecnológica Federal do Paraná (UTFPR) - Curitiba (PR), Brasil.
}

\section{Cláudio Fernando Mahler}

D.Sc. pelo COPE e Livre Docente pela Faculdade de Saúde Pública da USP. Professor de Engenharia Geotécnica e Coordenador do Grupo de Estudos de Tecnologia de Resíduos (GETRES) da UFRJ - Rio de Janeiro (RJ), Brasil.

\section{Juliana Lundgren Rose}

D.Sc. pelo COPPE da UFRJ. Pós-doutoranda em Geotecnia Ambiental e Membro do GETRES da UFRJ - Rio de Janeiro (RJ), Brasil.

\section{Resumo}

O controle da entrada de água de chuva no interior do aterro de resíduos sólidos urbanos durante sua construção e após seu fechamento é crucial para manter o controle da geração de lixiviado. Este fator pode contribuir para a elevação de gastos com tratamento e monitoramento e para a instabilidade mecânica do aterro. Por esta razão, o sistema de cobertura final de um aterro de resíduos sólidos urbanos é decisivo ao controle da entrada de água no mesmo. Na maioria dos casos, o sistema de cobertura final é composto por solo compactado. Frequentemente, um solo adequado para a cobertura não é encontrado nos arredores do aterro; portanto, recursos têm que ser despendidos para o transporte do mesmo até o devido local. Uma alternativa seria a utilização de uma barreira capilar construída com resíduos pré-tratados mecânica e biologicamente. No entanto, o uso deste material para esta construção ainda não foi bem estudado, e as diversas variáveis envolvidas no funcionamento de uma barreira capilar construída com resíduos sólidos pré-tratados mecânica e biologicamente são desconhecidas. O objetivo deste trabalho foi analisar os parâmetros envolvidos no funcionamento de uma barreira capilar construída exclusivamente de resíduos sólidos urbanos pré-tratados mecânica e biologicamente. Observou-se que este utilizado como material de uma barreira capilar pode funcionar de maneira equivalente àquela construída com solo, sendo boa a sua capacidade de retenção da água de chuva.

Palavras-chave: resíduos sólidos urbanos; pré-tratamento mecânico biológico; geotecnia ambiental.

\begin{abstract}
The control of rainwater entry into the municipal solid waste landfill during its construction and after its closure is crucial to keep track of leachate generation. This is a factor that may contribute to the increase of costs on treatment and monitoring and to the mechanical instability of the landfill. For this reason, the final cover system of a municipal solid waste landfill is critical for controling the water entering into the landfill. In most cases, the final cover system is made of compacted soil. Often, suitable soil for landfilling is not found in its surroundings, and resources must be expended in transporting the soil to the landfill site. An alternative would be to use a capillary barrier constructed with mechanical and biologically pretreated waste. However, the use of this material to construct capillary barriers has not been studied and several variables involved in the operation of a capillary barrier constructed with municipal solid mechanical and biologically pretreated waste landfill are unknown. The objective of this study was to analyze the parameters involved in the operation of a capillary barrier built exclusively solid waste pre-treated mechanically and biologically. It was observed that the MSW MBT used as a capillary barrier material may function similarly to that constructed with soil, with a good capacity for rain water retention.
\end{abstract}

Keywords: municipal solid waste landfill; mechanical biological pre-treatment; environmental geotechnic. 


\section{Introdução}

Um aterro de resíduo sólido urbano (RSU) implica em grandes desafios de logística, administração, construção e impacto social, os quais podem resultar em poluição do meio ambiente quando da falta de recursos financeiros, formação técnica dos funcionários responsáveis da Prefeitura, ou até mesmo, responsabilidade social ambiental.

Um dos principais elementos da construção de um aterro sanitário é a camada de cobertura final. Este elemento é importante, pois é responsável pelo controle da entrada de líquidos no interior da massa do aterro sanitário. Isso, em consequência, influi diretamente na geração de lixiviado, que, por sua vez, exerce influência em seus custos de tratamento durante a operação e após o fechamento do aterro sanitário. Neste sentido, papel semelhante é desempenhado também pela cobertura diária dos resíduos, que é realizada com o intuito de controlar vetores e mau cheiro; é construída com o aterro ainda em operação e não tem o mesmo rigor técnico dispensado à camada de cobertura final, porém uma das suas vantagens, assim como esta camada, é controlar a entrada de líquidos no aterro.

Normalmente, no Brasil, uma camada de solo compactado com baixa permeabilidade é usada para construir aquelas de coberturas diária e final, sendo a camada de cobertura final mais espessa e compactada do que as diárias.

A utilização de solo para estas finalidades de forma econômica compreende a disponibilidade de jazidas próximas ao aterro sanitário, o que raramente ocorre. Além disso, solos com tais características podem ser considerados como uma matéria-prima "nobre" para ser utilizado na cobertura de um aterro sanitário. Existem alternativas como, por exemplo, barreiras asfálticas, com rejeitos de mineração e capilares feitas com solo. Uma boa solução seria a possibilidade de construir a camada de cobertura final usando RSU pré-tratado. A tecnologia de barreiras capilares, comumente construídas com solo, se vale de certas faixas granulométricas a fim de criar uma hidráulica, controlando assim a passagem de líquidos. Ao invés de solo, a utilização de RSU pré-tratado mecânica e biologicamente (PTMB) para construir uma barreira capilar como cobertura final em um aterro sanitário seria uma solução vantajosa em vários aspectos.

\section{Objetivo}

O presente trabalho teve como objetivo principal avaliar a aplicação de RSU PTMB como material de construção de uma barreira capilar para ser utilizada como cobertura final de aterros sanitários, investigando os parâmetros envolvidos em seu funcionamento.

\section{Funcionamento de uma barreira capilar}

O objetivo de um sistema de cobertura é minimizar o volume de água que se infiltra no aterro e atinge as camadas subjacentes. Isto é, em geral, atingido por meio da seleção de solos com baixa condutividade hidráulica e/ou membranas de polietileno de alta densidade (PEAD), juntamente com sistemas de drenagem instalados antes e depois dos sistemas de cobertura. $\mathrm{O}$ fenômeno físico presente em uma barreira capilar é totalmente diferente daquele de um sistema de cobertura convencional. Alguns autores, como Khire et al. (2000), Vieira (2005), Weiß e Witzsche (2005) e Suzuki et al. (2005), vêm estudando aquelas construídas com solo ou materiais similares, assim como sua aplicação como sistema de cobertura final em aterros sanitários.

Uma barreira capilar é um sistema composto por duas camadas de materiais com granulometrias diferentes. Basicamente, é uma com um material de granulometria mais fino sobre outro grosso. As duas camadas podem ser construídas com o mesmo ou com materiais diferentes, dependendo das propriedades de cada um a ser utilizado.

Embora as forças ativas em ambos os instrumentos sejam as mesmas, o teor de umidade é muito diferente na proximidade de seu contato. O teor de umidade volumétrica na camada capilar é sempre mais elevado do que naquela de bloqueio capilar subjacente, de modo que a permeabilidade hidráulica não saturada na camada capilar é mais elevada. Isto significa que um fluxo de água ainda pode ocorrer, enquanto que nenhum movimento da água ocorrerá na camada de bloqueio. Para permitir um fluxo livre de água na camada capilar, uma inclinação mínima entre 10 a $20^{\circ}$ é necessária. Na zona de contato entre os dois materiais, a mudança brusca, entre poros pequenos na camada capilar e mais largos na de bloqueio, resulta no efeito final que é a não passagem de líquidos para as camadas subjacentes. Somente quando a coluna de água for suficientemente grande, ao ponto da pressão de água superar a força capilar, ocorrerá, então, a passagem de líquido em uma barreira capilar.

Em suma, seu primeiro efeito é a retenção de água na camada superior e o segundo, o fluxo livre horizontal da água na mesma camada. Por causa destes, a retenção de água devido à diferença no tamanho dos poros dos dois materiais e à permeabilidade não saturada mais elevada da camada capilar, é possível dividir os fenômenos atuantes em uma barreira capilar entre fenômenos unidimensionais e bidimensionais. Assim, o primeiro é a simples retenção da água devido às forças da capilaridad e o bidimensional é a drenagem dos líquidos de um ponto mais elevado a um ponto mais baixo.

Observa-se na Figura 1 o princípio de funcionamento bidimensional da barreira capilar. Quando a precipitação ocorre, a água alcança a camada capilar e começa a se infiltrar e, ao mesmo tempo, seu

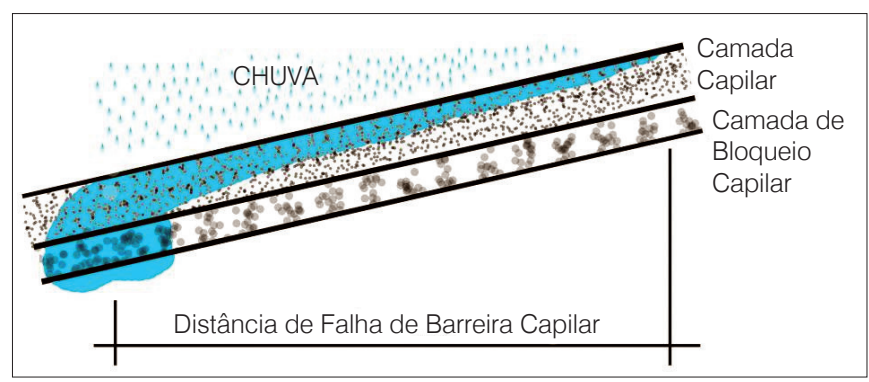

Figura 1 - Representação da distância de falha em uma barreira capilar. 
excesso começa a fluir lateralmente. Em algum momento, a camada capilar atinge sua capacidade máxima de retenção da água e, assim, a pressão torna-se positiva e o efeito capilar da ascensão desaparece. Consequentemente, a água está livre para passar e alcançar o bloco capilar. Cabral et al. (2007) estudaram uma maneira de prever a chamada distância de desvio em uma barreira capilar construída com subprodutos de processos de retirada de tinta (DBP), em um experimento montado em um aterro sanitário em Quebec, no Canadá. A complexidade dos fenômenos faz com que sua predição fique muito difícil, mesmo quando o material de construção da barreira capilar é um solo.

A heterogeneidade de tal RSU tratado mecânica e biologicamente é o grande problema para projetar uma barreira capilar construída de RSU PTMB. A composição do material e sua compactação têm uma influência nos parâmetros como permeabilidade saturada e não saturada, porosidade, distribuição granulométrica e estabilidade da partícula, capacidade de campo etc. Esse fato introduz um grande número de variáveis. Em relação à mudança de tamanho da partícula, quando o RSU tratado usado é essencialmente composto por material oriundo de matéria orgânica, sem, ou quase sem, nenhuma partícula de plástico, vidro, madeira ou rochas, as mudanças na distribuição granulométrica se processam de forma mais rápida. Estas podem ser mais drásticas devido à quebra mecânica das partículas de origem orgânica causadas, por exemplo, pela manipulação excessiva do material, pela aplicação da carga ou pela decomposição natural devido ao processo de intemperismo.

\section{Metodologia}

Para alcançar o objetivo da pesquisa, a análise granulométrica, o coeficiente de permeabilidade e a capacidade de campo do RSU PTMB foram obtidos por meio dos ensaios de laboratório. Posteriormente, com o intuito de avaliar as variáveis envolvidas no comportamento da barreira capilar proposta, realizou-se um ensaio unidimensional e construiu-se uma barreira capilar experimental em laboratório.

\section{Resíduo sólido urbano pré-tratado mecânica e biologicamente}

Mesmo após um tratamento como o PTMB ou a compostagem, o RSU continua sendo um material muito heterogêneo. A distribuição granulométrica e o aspecto das partículas das diferentes faixas granulométricas do que foi estudado podem ser observados na Figura 2. A amostra coletada foi pré-peneirada, no local de coleta, com peneiras de malha com abertura de 10 (S02-T01 e S02-T02) e 22 mm (S02-T03, S02-T04 e S02-T05).

Em laboratório, o RSU PTMB passou pelo mesmo processo. Foram reservados para os ensaios os instrumentos que passaram na peneira com abertura de $4 \mathrm{~mm}$ e aquele retido na peneira com 9,52 mm (Figura 3). Sabe-se que, com o pré-tratamento do RSU, a distribuição granulométrica, a configuração das partículas e as suas

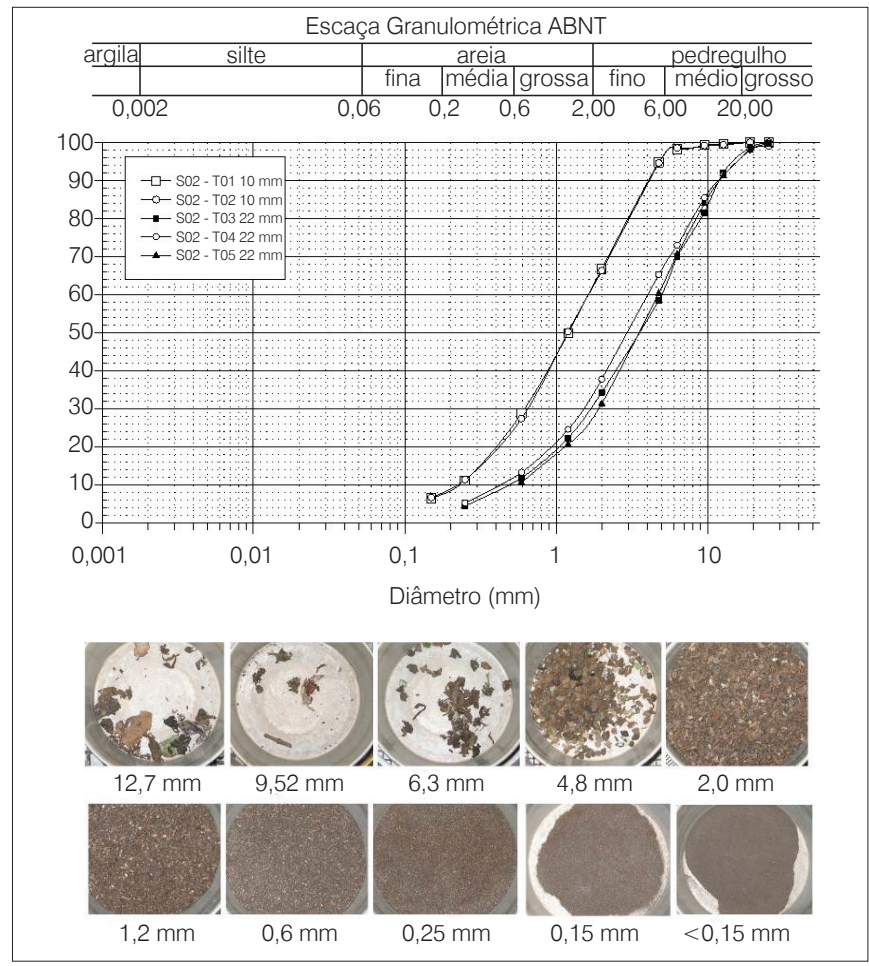

Figura 2 - Curvas granulométricas das amostras de resíduo sólido prétratado mecânica e biologicamente coletadas.

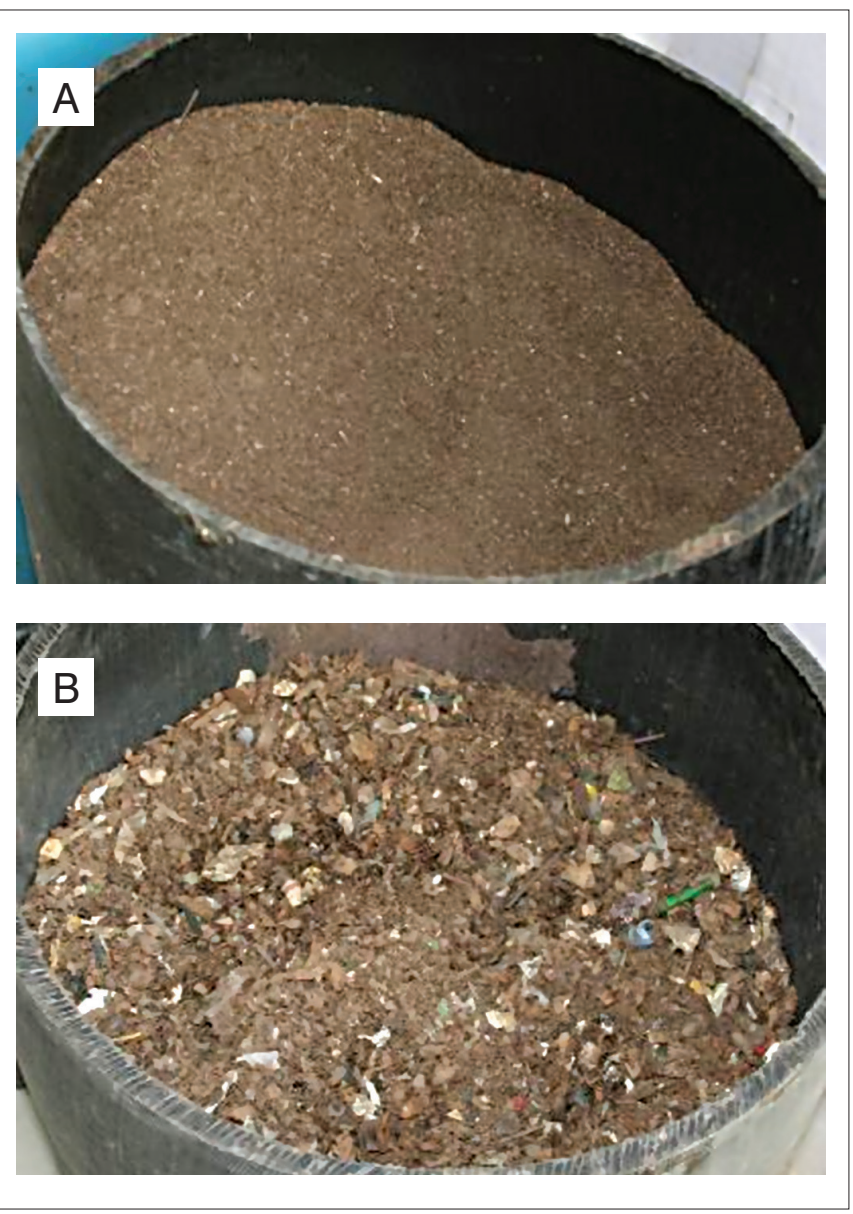

Figura 3-Resíduo sólido urbano pré-tratado mecânica (A) e biologicamente (B) com diâmetro máximo de 4 e 9,52 mm, respectivamente. 
propriedades sofrem grandes mudanças. Na Figura 4 é possivel observar uma partícula do RSU PTMB, na qual existe metal com matéria orgânica e substância mineral aderida à superfície do metal, indicando que a partícula resultante é uma espécie de combinação dos elementos do RSU original.

Tal combinação de diferentes materiais na composição das partículas do composto ocasiona um comportamento diferente do que o esperado para um solo, sendo um resultado da interação de diversos processos, dos quais os mais importantes são a fragmentação mecânica, a atividade microbiológica e os processos químicos. Como consequência, o composto apresenta grandes diferenças em relação à porosidade e ao formato das partículas, quando comparado a um solo. Essas diferenças afetam propriedades, tais como permeabilidade de gases e líquidos, adensamento, teor de umidade e comportamento mecânico, o que justifica os esforços de autores como Staub et al. (2009), Münnich et al. (2009) e Zardava et al. (2009) em entender tais mudanças nas características deste material.

A agregação de material orgânico com partículas minerais também ocorre, como pode ser observado na Figura 5. Neste caso, ela apresenta pequenas fissuras, devido à sua constituição ou à fragmentação mecânica, as quais, juntamente com outras evidências, levam a crer que o RSU tratado possui uma macro e uma microporosidade. Esta microporosidade pode ser entendida como a porosidade da própria partícula e os vazios das aglomerações de matéria orgânica.

\section{Ensaio de permeabilidade}

Ensaios de permeabilidade saturada à carga constante foram realizados a fim investigar a variação do coeficiente da permeabilidade em função da variação da massa específica seca do RSU tratado.

Os corpos de prova para a realização dos ensaios de permeabilidade foram moldados na umidade ótima, com variações apenas nas massas específicas secas, a saber: dois com 60 e 80\% do valor da massa específica ótima, respectivamente, e um terceiro no mesmo tipo. Essas variações nas densidades tiveram por finalidade analisar diferentes condições nas quais o material estivesse no estado fofo, medianamente compacto e compacto, respectivamente. Os corpos de prova foram moldados em cilindros de diâmetro de $10,15 \mathrm{~cm}$ e altura de $10,15 \mathrm{~cm}$.

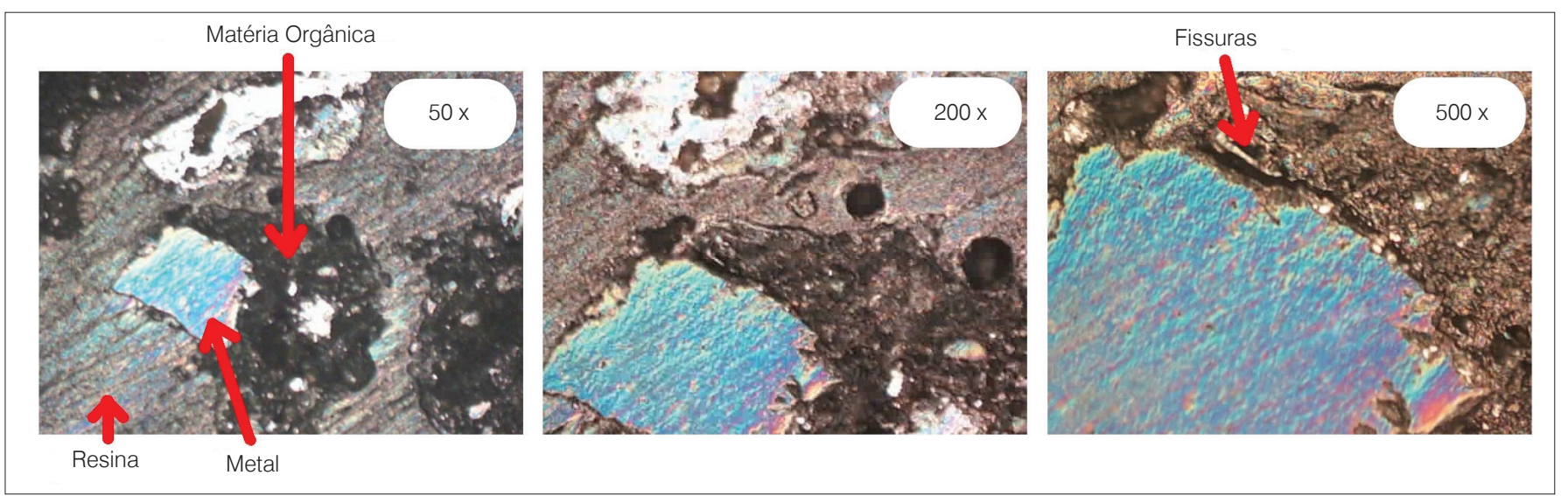

Figura 4 - Imagem de microscopia óptica de uma partícula de resíduo sólido urbano pré-tratado mecânica e biologicamente.

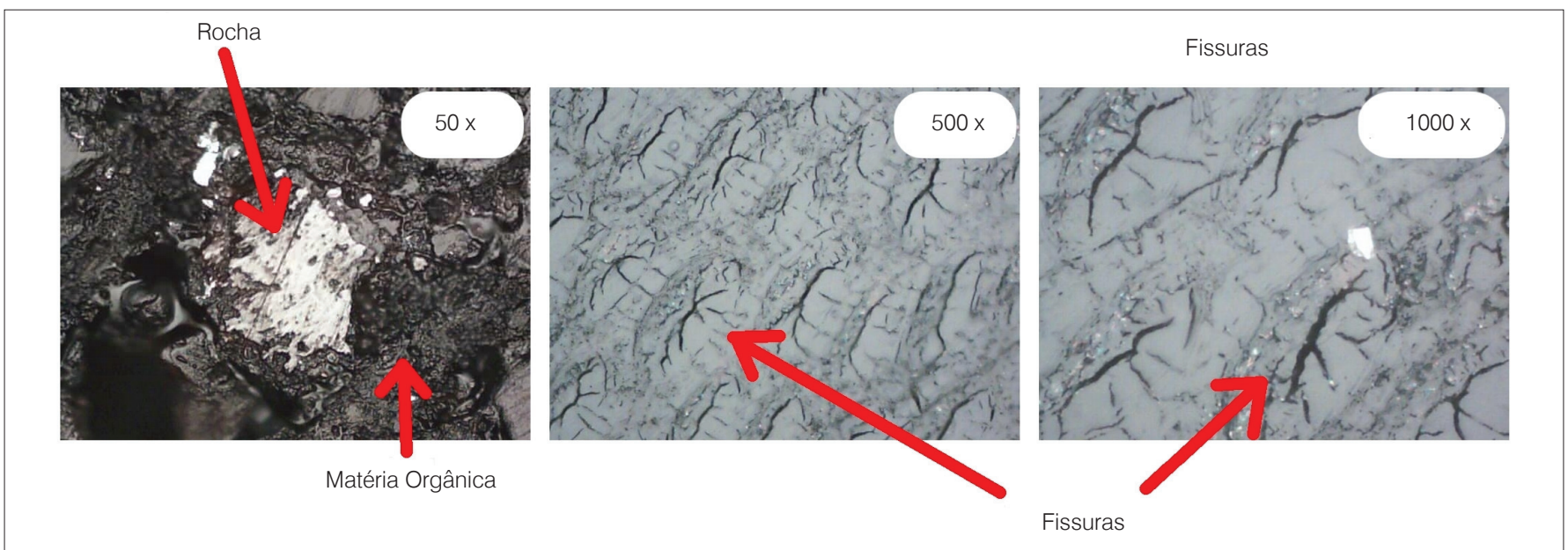

Figura 5 - Imagem de microscopia óptica de uma partícula mineral encontrada em resíduo sólido urbano pré-tratado mecânica e biologicamente ampliada 50, 500 e 1.000 vezes. 


\section{Capacidade de campo}

Ao final de cada ensaio de permeabilidade, retirou-se o cilindro contendo o corpo de prova de dentro d'água. Este cilindro era deixado em cima da bancada para que a água excedente drenasse por um determinado período, que era determinado pela quantidade de água que escoava do corpo de prova. O líquido era coletado em uma proveta para que houvesse monitoramento do volume de água excedente. Quando esta vazão fosse menor do que 0,01 mL.s ${ }^{-1}$, o cilindro era desmontado e amostras do material eram retiradas para a verificação da umidade correspondente à capacidade de campo (ROCHA $\&$ AZEVEDO, 2008). Seis amostras foram coletadas, sendo duas do topo, duas do meio e duas da base do corpo de prova.

Para a determinação da capacidade de campo, utilizou-se a seguinte relação, apresentada pela da Equação 1:

$\theta=\frac{\rho_{t} \times \omega_{\theta}}{\left(1+\omega_{i}\right) \times \rho_{a}}$

onde, $\theta$ é a capacidade de campo; $\rho$ d representa a massa específica seca (g.m $\left.\mathrm{m}^{-3}\right)$; $\rho$ a é a massa específica da água (g.m $\left.{ }^{-3}\right) ; \omega \theta$ indica a umidade de campo; $\rho$ d é a massa específica seca (g.m $\left.\mathrm{m}^{-3}\right)$; $\rho$ t é a massa específica total (g.m $\left.{ }^{-3}\right)$ e $\omega$ i, umidade inicial.

\section{Ensaio unidimensinal}

O fenômeno unidimensional que ocorre em uma barreira capilar pode ser explicado como a simples retenção dos líquidos por capilaridade na barreira. Isto permite a evaporação do líquido retido após uma chuva, por exemplo, durante um período, sendo também a razão pela qual a barreira capilar é considerada uma camada evapotranspirativa de cobertura.

Para a realização deste ensaio, um tubo de plástico com 4,21 cm de diâmetro interno e $61,5 \mathrm{~cm}$ de altura foi preso por uma garra, que por sua vez estava ligada a um suporte montado sobre uma balança, e uma bureta foi colocada na parte superior da coluna para simular um evento de chuva (Figura 6). A velocidade da entrada de água foi imposta como constante e muito lenta, a uma taxa de aproximadamente $10^{-5} \mathrm{~m} \cdot \mathrm{s}^{-1}$. Neste ensaio, a coluna foi montada com três valores diferentes de massa específica seca para construir a camada capilar.

Permitiu-se que a água infiltrasse na camada capilar até que a mesma alcançasse a camada de bloqueio e uma passagem de água fosse observada. Quando isto ocorria, o fluxo de água era então interrompido e a coluna desmontada, sendo o teor de umidade do RSU PTMB medido a cada $5 \mathrm{~cm}$.

\section{Barreira capilar experimental}

A fim de analisar as variáveis envolvidas no processo de funcionamento de uma barreira capilar construída com o RSU tratado, um modelo em escala de laboratório foi construído e submetido a diferentes condições de trabalho. O modelo, suas dimensões e detalhes do sistema de aspersão utilizado para simular chuva podem ser observados na Figura 7 .

As dimensões da caixa utilizada para montar a barreira capilar com RSU pré-tratado são 1,80 por $0,60 \mathrm{~m}$ de largura e 0,44 m de profundidade.

Os ensaios realizados neste modelo em escala de laboratório foram conduzidos de forma a variar apenas um único elemento durante uma série. O primeiro parâmetro estudado foi a inclinação da barreira capilar e sua influência na quantidade de líquido coletada pela drenagem da camada capilar e naquela retida.

Foram realizados três ensaios, com inclinações de 5, 10 e $1^{\circ}$, para camada capilar com composto de granulometria menor de 4 mm e três outros, com 5, 10 e $15^{\circ}$, para camada capilar com granulometria menor do que $2 \mathrm{~mm}$.

Em seguida, mantendo uma inclinação de $20^{\circ}$, variou-se o tempo de chuva aplicada sobre a superfície da camada capilar. A barreira capilar foi submetida a 2, 1,5 e 1 hora de tal fenômeno.

Ainda com a inclinação de $20^{\circ}$, para avaliar a diminuição da velocidade de infiltração sobre a camada capilar, aplicou-se o volume correspondente a duas horas de chuva, em um período de quatro horas. Isto foi realizado ligando e desligando os aspersores de cinco em cinco minutos, por quatro horas.

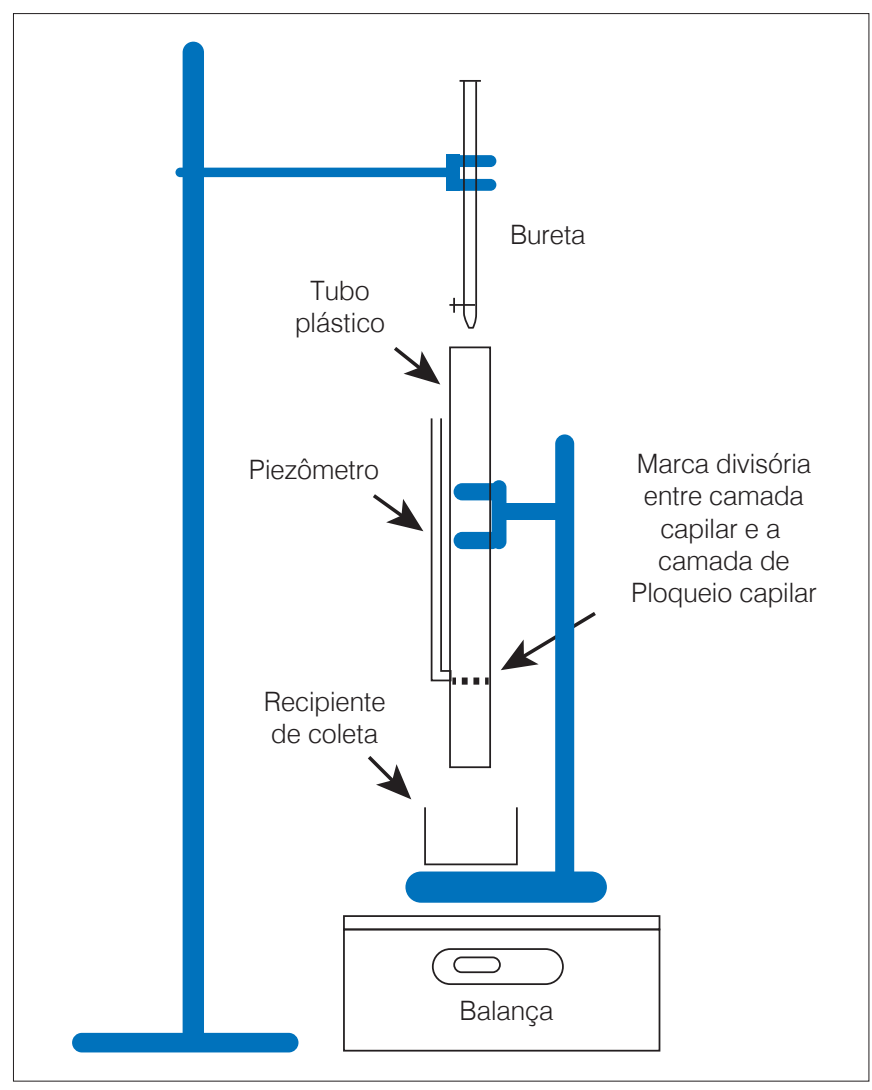

Figura 6 - Esquema de montagem do ensaio para estudar a retenção unidimensional de líquidos em uma barreira capilar feita com resíduo sólido urbano pré-tratado mecânica e biologicamente. 

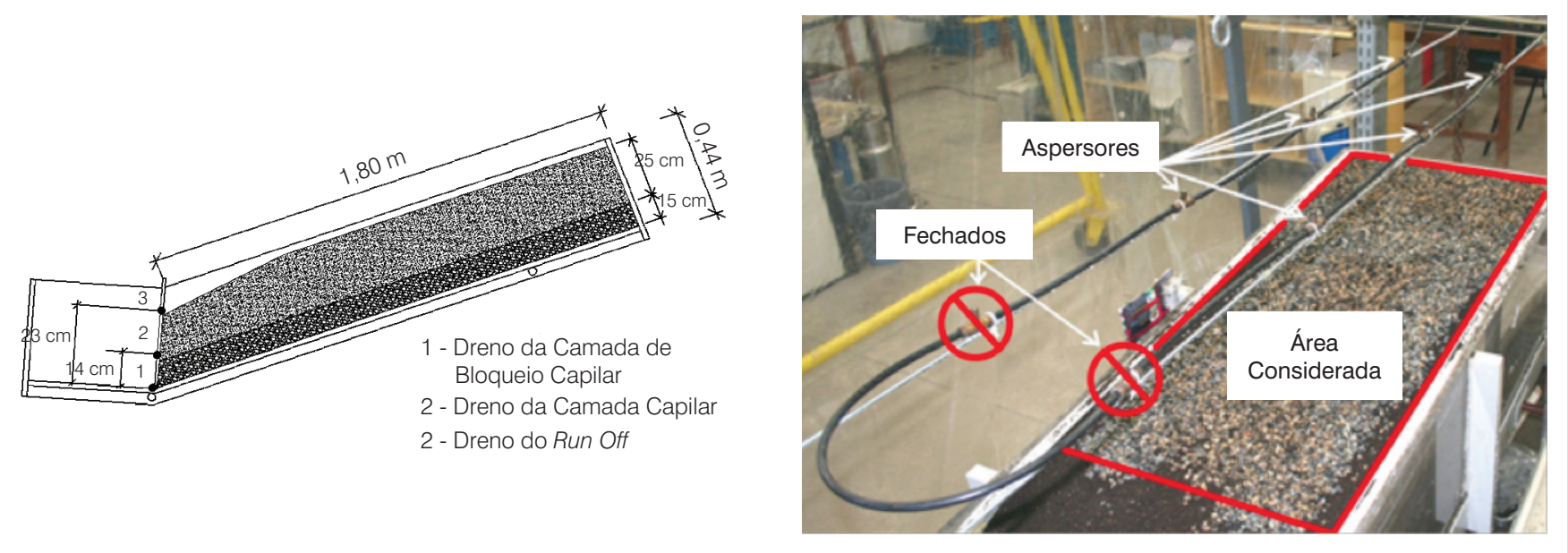

Figura 7 - Modelo em escala de laboratório para estudar as variáveis envolvidas no processo de funcionamento de uma barreira capilar construída com resíduo sólido urbano pré-tratado mecânica e biologicamente.

Todo o procedimento foi realizado para uma barreira capilar com camada capilar medindo $25 \mathrm{~cm}$ de altura e bloco capilar com $12 \mathrm{~cm}$ de altura.

Visando verificar o efeito do aumento do grau de compactação da camada capilar, impôs-se uma compactação manual à mesma, cuja massa específica seca passou de 0,55 para $0,70 \mathrm{~g} . \mathrm{cm}^{-3}$. Posteriormente, repetiu-se a aplicação de chuva em diferentes tempos.

Após a compactação, a altura da camada capilar foi reduzida para $16 \mathrm{~cm}$ de altura, sendo que o bloco capilar ficou com os mesmos $12 \mathrm{~cm}$. Para completar o espaço que sobrou, devido à redução da altura da camada capilar, colocou-se outra de RSU tratado, com partículas menores do que $4 \mathrm{~mm}$, em seu topo. Optou-se por esta solução, pois não haveria quantidade suficiente de material com partícula menor do que $2 \mathrm{~mm}$ se fosse realizado um peneiramento. Vale ressaltar que todo o material utilizado é originário da mesma amostra coletada no início desta pesquisa.

\section{Resultados}

\section{Compactação}

Para se definir os parâmetros utilizados com os experimentos com a barreira capilar construída com RSU PTMB, foram realizados ensaios de compactação, permeabilidade e capacidade de campo.

Pela análise da curva de compactação, realizada com energia de compactação normal (Figura 8), determinou-se que a massa específica aparente seca máxima para este material é de $0,818 \mathrm{~g} . \mathrm{cm}^{-3}$ e que a umidade ótima (base úmida) é de 39,4\%.

Observa-se na Figura 8 certa dispersão dos valores obtidos nos ensaios de compactação (Proctor normal) com este RSU PTMB.

\section{Ensaio de permeabilidade}

Os resultados dos ensaios de permeabilidade à carga constante, em função da massa específica seca, podem ser observados na Figura 9.

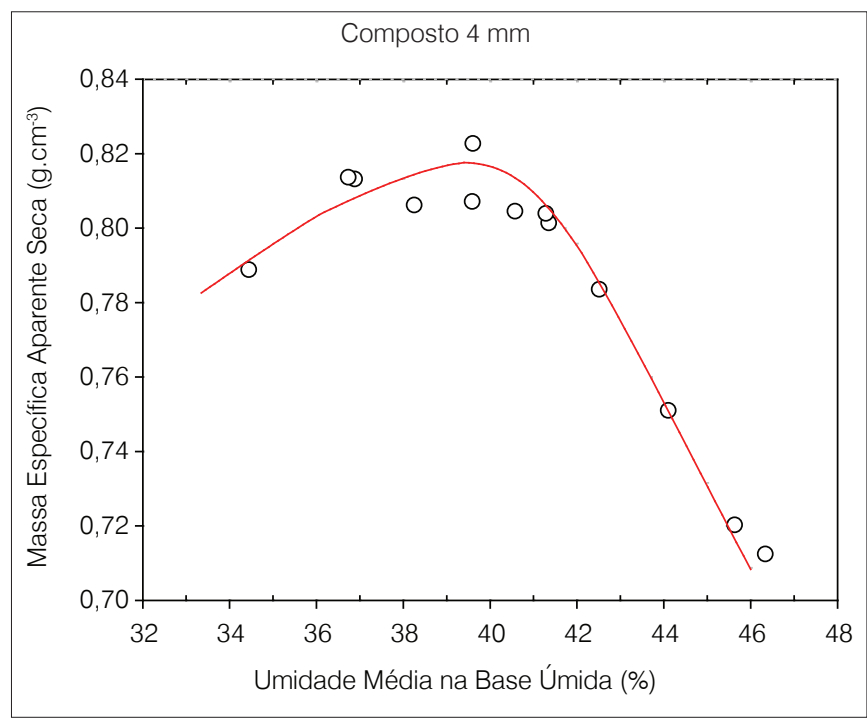

Figura 8 - Ensaio de compactação realizado com resíduo sólido urbano pré-tratado mecânica e biologicamente com partículas menores do que $4 \mathrm{~mm}$.

Os valores encontrados para o coeficiente de permeabilidade do RSU PTMB estudado neste trabalho são similares aqueles encontrados por Staub et al. (2009), que apresentaram resultados com densidades diferentes. Staub et al. (2009) encontraram coeficientes de permeabilidade de $7^{*} 10^{-3}$ a $1^{*} 10^{-4} \mathrm{~cm} \cdot \mathrm{s}^{-1}$ para uma massa específica seca de 0,36 a 0,53 g. $\mathrm{cm}^{-3}$, enquanto que, para o RSU PTMB estudado, os valores ficaram entre $4^{*} 10^{-4}$ e $1,8^{*} 10^{-6} \mathrm{~cm} \cdot \mathrm{s}^{-1}$, para uma massa específica seca entre 0,49 a $0,82 \mathrm{~g} \cdot \mathrm{cm}^{-3}$. Geralmente, o mesmo fenômeno é observado, ou seja, com o aumento da massa específica o volume de vazios diminui e, consequentemente, restringe a passagem do líquido pelo meio.

\section{Capacidade de campo}

Os resultados da capacidade de campo em relação à massa específica seca do RSU tratado, que foram obtidos a posteriori dos ensaios de permeabilidade, podem ser observados na Figura 10. 


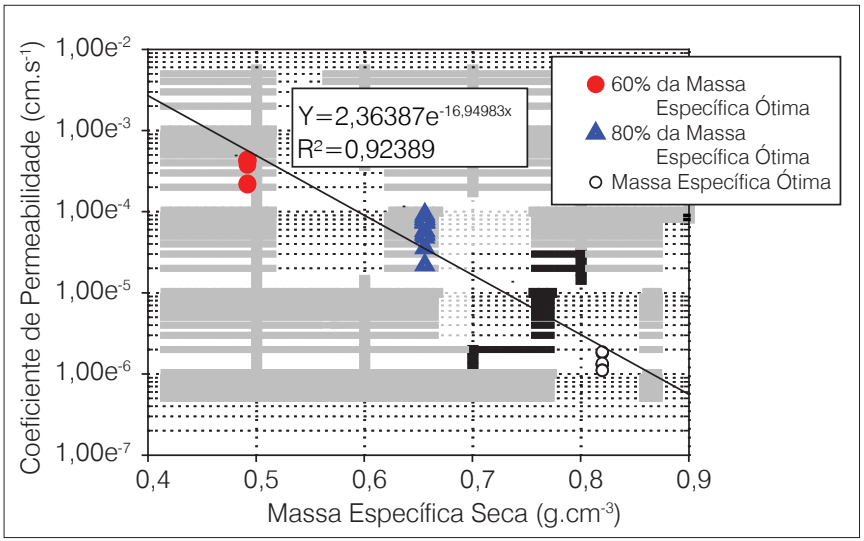

Figura 9 - Ensaio de permeabilidade à carga constante realizado com resíduo sólido urbano pré-tratado mecânica e biologicamente com partículas menores do que $4 \mathrm{~mm}$.

De acordo com os resultados, a capacidade de campo diminui com o aumento da massa específica seca. Este resultado era esperado já que o aumento da massa específica causa uma diminuição do volume de vazios, reduzindo o volume disponível para reter líquidos.

\section{Ensaio unidimensinal}

Os resultados dos ensaios unidimensionais podem ser observados na Figura 11. O volume de vazios na camada capilar compactada com $100 \%$ do grau de compactação foi cerca de 18\% menor do que aquela com 60\%. Por outro lado, como apresentado na Tabela 1, a massa de água retida pela camada capilar com um grau de compactação de $100 \%$ foi aproximadamente 35\% mais elevada do que aquela com $60 \%$. Isto significa que, embora o volume inicial de vazios na barreira capilar com 100\% do grau de compactação seja menor, a capacidade de retenção de água aumenta devido ao efeito da capilaridade e, no final, o volume de vazios ocupado pela água é maior, sendo a capacidade de retenção da água por volume de RSU tratado maior.

Pela análise dos resultados obtidos e considerando uma área de $1 \mathrm{~m}^{2}$ de uma barreira capilar construída com RSU PTMB, uma altura de $25 \mathrm{~cm}$ e com um grau de compactação de $100 \%$, a quantidade de água que esta barreira capilar poderia reter seria equivalente a uma chuva de 129,7 mm.

\section{Barreira capilar experimental}

Os resultados dos ensaios realizados com a barreira capilar experimental podem ser observados nas Figuras 12 a 14. Eles apresentam uma grande dispersão, muito provavelmente devido ao material em si, mas apesar disso, é possível observar tendências de comportamento, as quais são explicitadas pelas retas traçadas nas Figuras 12 a 14. Desse modo, observa-se, na Figura 12, que com o aumento da inclinação, mais líquido é escoado lateralmente e, consequentemente, mais líquido é coletado por meio da drenagem da camada capilar. Por outro

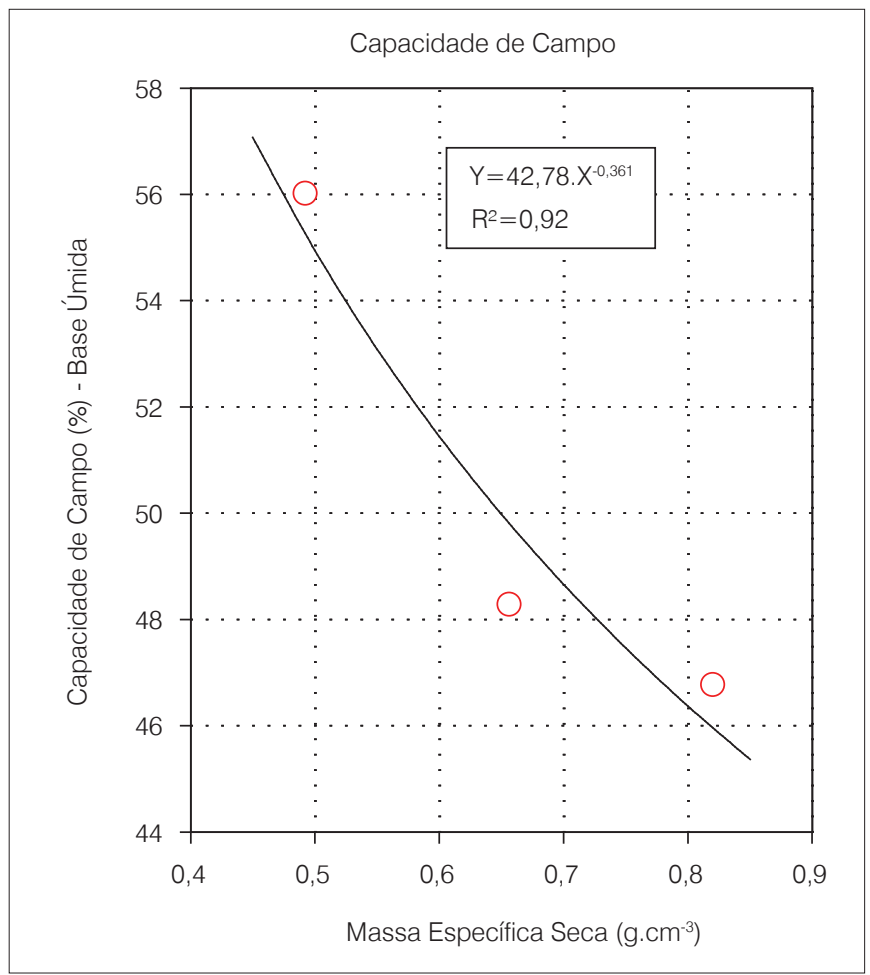

Figura 10 - Capacidade de campo obtido para resíduo sólido urbano pré-tratado mecânica e biologicamente após ensaio de permeabilidade saturada à carga constante.

lado, com o aumento da inclinação, menos líquido é retido na camada capilar por causa do efeito de drenagem lateral.

Outro parâmetro estudado foi a variação da massa específica seca, ou seja, do grau de compactação da camada capilar. Os resultados desta série de ensaios podem ser observados na Figura 13.

Novamente, é possível inferir que quanto maior a massa específica seca, menor é a quantidade de água coletada pelo dreno da camada capilar devido à permeabilidade não saturada horizontal ser reduzida com a compactação do material. Em relação à quantidade de água retida na camada capilar, esta será maior com o aumento da massa específica seca, devido ao efeito da capilaridade. Esse fenômeno foi também observado nos resultados dos ensaios unidimensionais.

Além da inclinação e da massa específica seca da barreira capilar, outra importante variável é a intensidade de chuva. Na Figura 14 é apresentada a variação da intensidade de chuva em função da água coletada pelo dreno da camada capilar e da água coletada pelo dreno da camada de bloqueio capilar para o teste em escala de laboratório conduzido. Apesar do número reduzido de ensaios e da sua relativa elevada dispersão, é possível ter um vislumbre da diminuição do volume de água retido pela camada capilar devido à elevação da intensidade de chuva. Tal fato ocorre porque o aumento do volume de água que alcança a camada capilar força o surgimento de caminhos preferenciais de fluxo, impedindo que a água seja homogeneamente distribuída no material da barreira capilar, causando uma redução do que é retido pela camada 


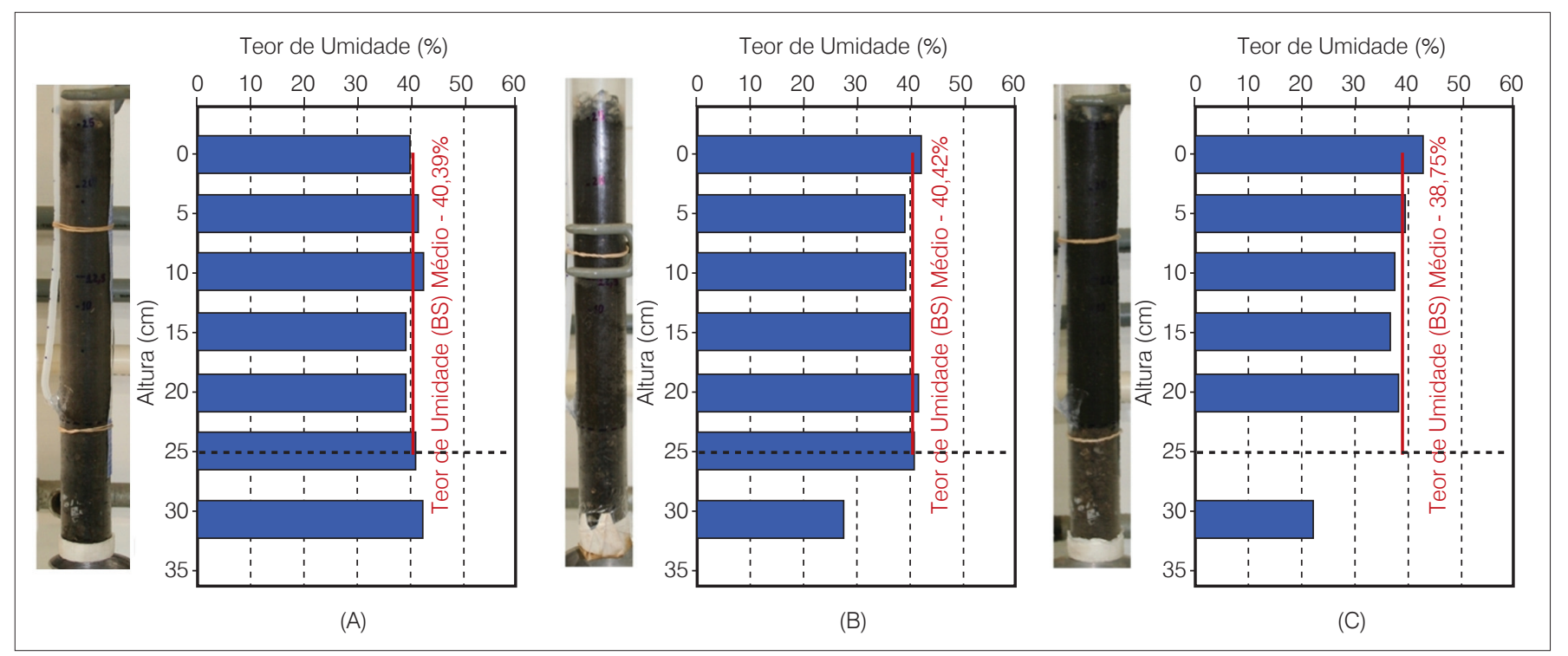

Figura 11 - Resultado dos ensaios unidimensionais em barreira capilar moldada com resíduo sólido urbano pré-tratado mecânica e biologicamente, com graus de compactação de 60 (A), 80 (B) e 100\% (C).

Tabela 1 -Resultados dos ensaios unidimensionais realizados para uma barreira capilar construída com resíduo sólido pré-tratado mecânica e biologicamente.

\begin{tabular}{|c|c|c|c|c|c|c|c|}
\hline Ensaio & $\begin{array}{c}\text { Massa } \\
\text { Específica Seca }\end{array}$ & $\begin{array}{l}\text { Volume de } \\
\text { Vazios Inicial }\end{array}$ & Massa Seca & $\mathbf{w}_{\text {inicial }}$ & $\mathrm{w}_{\text {final }}$ (médio) & $\begin{array}{c}\text { Massa de } \\
\text { Água Retida }\end{array}$ & $\begin{array}{l}\text { Total do Volume de Vazios } \\
\text { Ocupado por Água }\end{array}$ \\
\hline 1 & 0,82 & 197,98 & 285,37 & 16,1 & 38,7 & 180,52 & 91,2 \\
\hline 3 & 0,57 & 244,10 & 197,65 & 24,8 & 40,4 & 133,93 & 54,9 \\
\hline
\end{tabular}

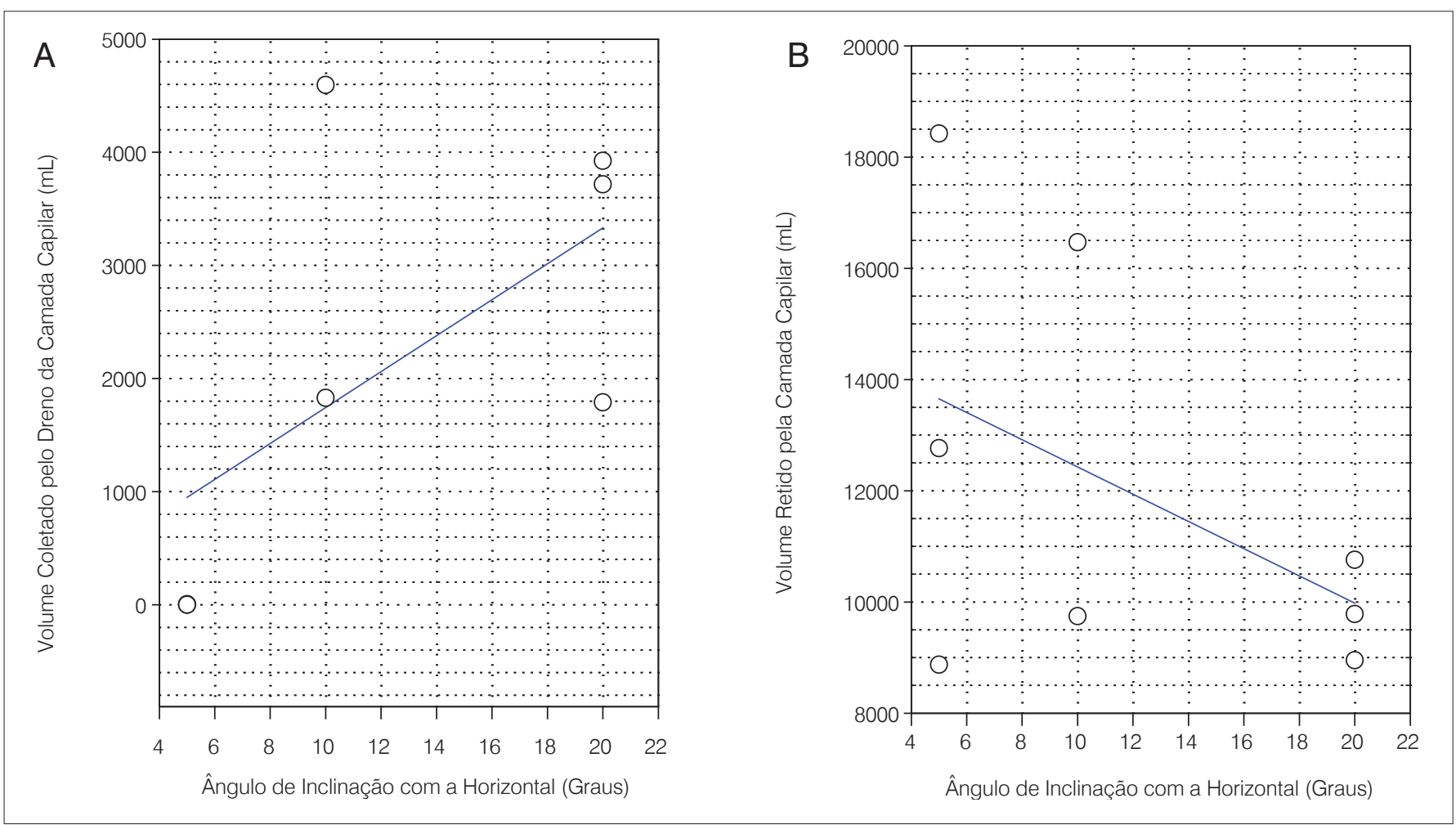

Figura 12 - Resultados dos ensaios de influência da inclinação no modelo de escala de laboratório de uma barreira capilar feita de resíduo sólido urbano pré-tratado mecânica e biologicamente. 


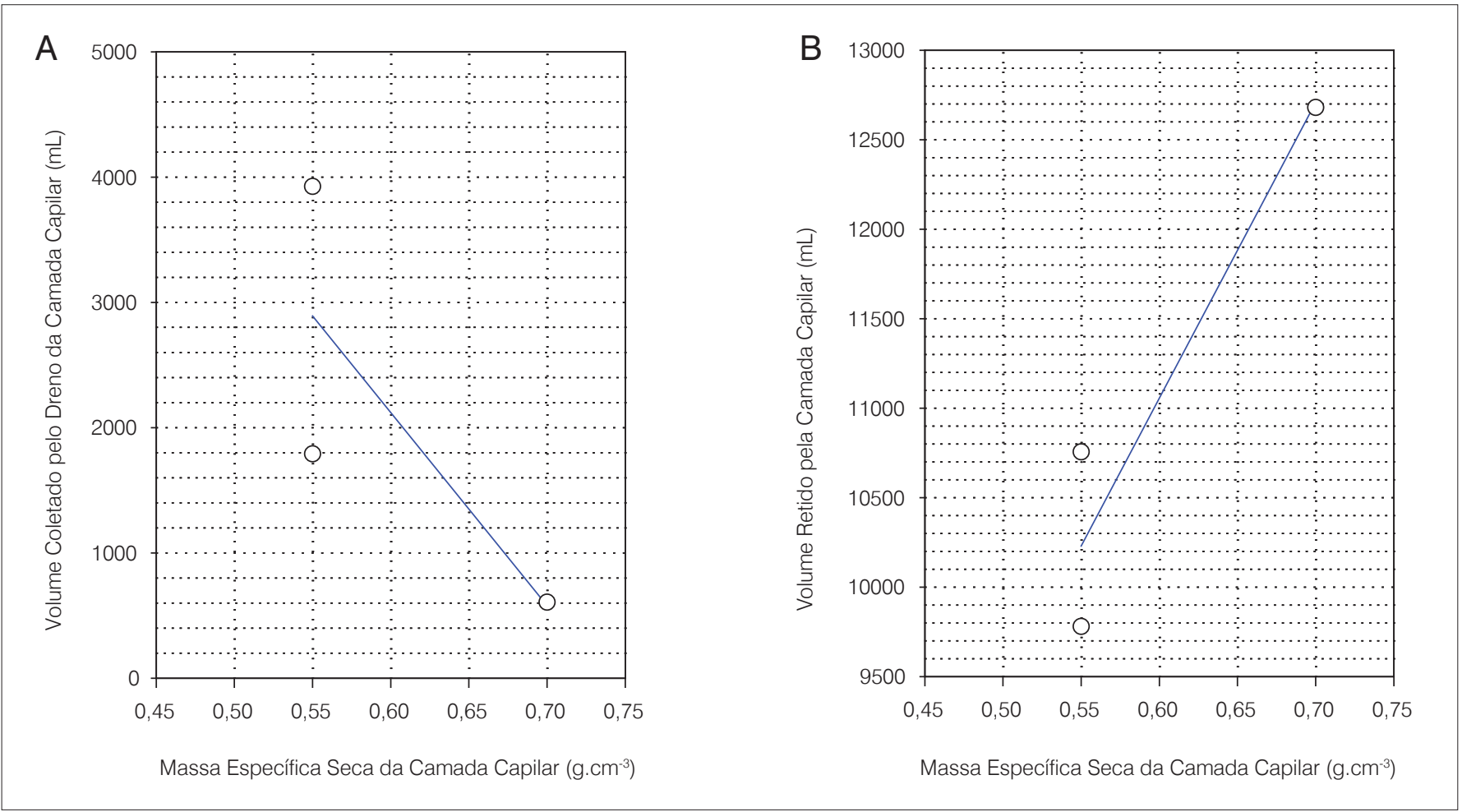

Figura 13 - Influência de variação da massa específica no modelo de escala de laboratório de uma barreira capilar feita de resíduo sólido urbano prétratado mecânica e biologicamente.

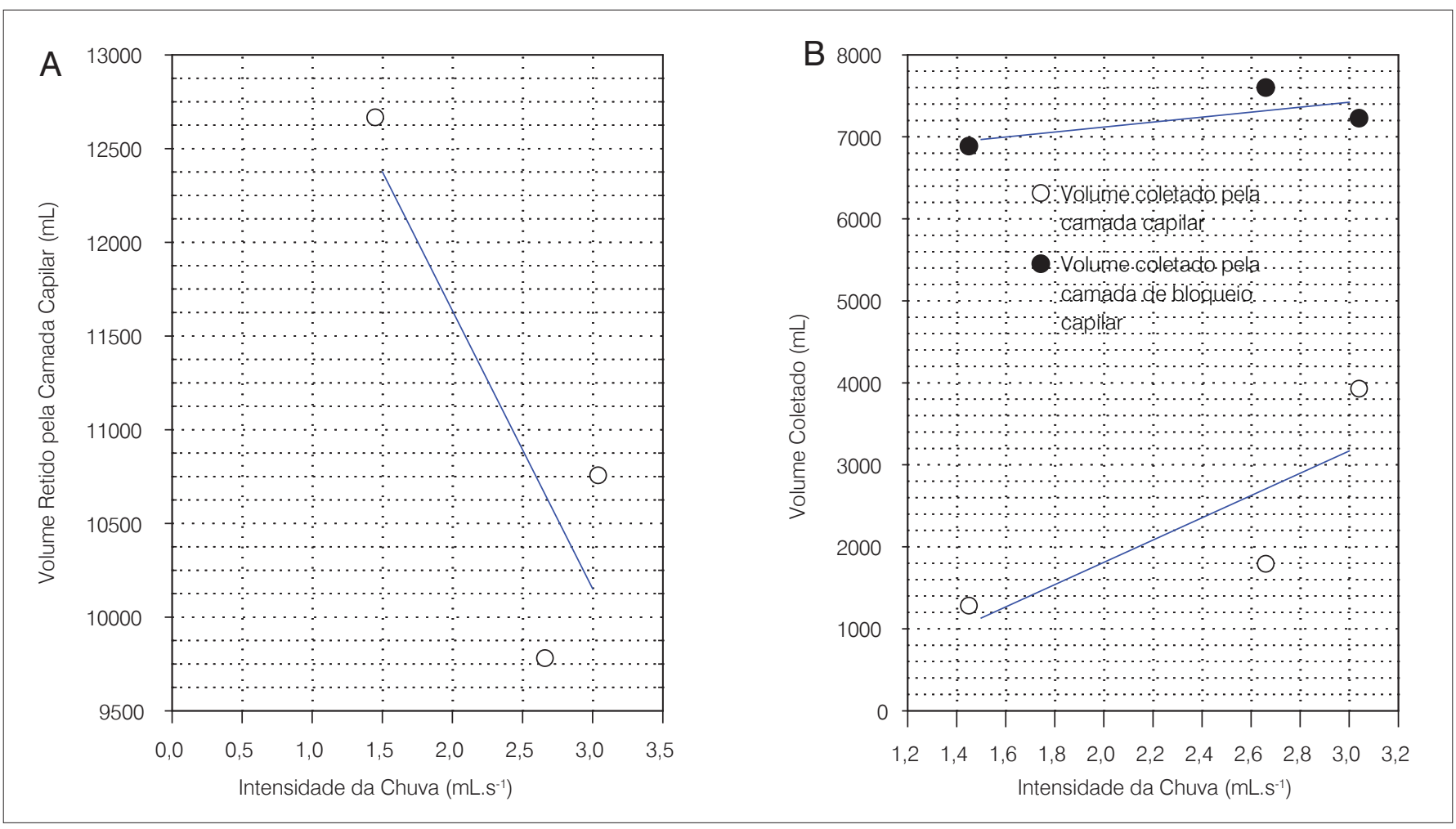

Figura 14 - Intensidade da chuva versus volume de água retido pela camada capilar e o volume de água coletado pelos drenos das camadas capilar e bloqueio capilar. 
capilar. De uma maneira análoga, o aumento do volume de água coletado pelas camadas capilar e de bloqueio pode ser explicado. Assim, neste ensaio em particular, quanto mais água passou pelos caminhos preferenciais, menos ficou retida na camada capilar e mais foi coletada pelos sistemas de drenagem, sendo que o maior aumento da coleta de água foi pelo sistema de drenagem da camada de bloqueio capilar.

A capacidade de retenção da barreira capilar construída com RSU PTMB, para as condições estudadas, não foi comparável aos 99\% de retenção observada por Weiß e Witzsche (2005) ou aos 100\% de Krisdani et al. (2005) em barreiras capilares experimentais que foram construídas com solo em aterros sanitários da Alemanha. Tal fato se deve às diferenças dos materiais utilizados para construir a barreira capilar (solo residual, no caso de KRISDANI et al., 2005) e na intensidade pluviométrica sobre as barreras capilares, que no caso deste trabalho foi superior. Além disso, vale comentar que a camada capilar utilizada por Weiß e Witzsche (2005) foi construída com uma espessura de $40 \mathrm{~cm}$, enquanto a barreira estudada neste trabalho tinha $25 \mathrm{~cm}$ de espessura (Figura 7).

Por fim, alguns autores como Weiß e Witzsche (2005) e Cabral et al. (2007) recomendam uma camada denominada de balanço hídrico acima da capilar, o que no caso particular da barreira capilar de RSU PTMB pode ser bastante interessante.

\section{Conclusões}

Os ensaios conduzidos neste trabalho propiciaram identificar as variáveis que estão envolvidas em uma barreira capilar construída com RSU PTMB, tendo havido, contudo, certa dispersão dos resultados, devido à natureza do material e, talvez, em função do mecanismo responsável por simular a chuva. Este mecanismo não permitiu um bom controle da intensidade e da distribuição da chuva, fatores estes relevantes para o estudo de uma barreira capilar de material de PTMB.

A inclinação e o grau de compactação são os parâmetros que influenciam a eficiência da barreira capilar. Do mesmo modo, o fenômeno unidimensional, ou simples retenção, parece ser o mais significativo que atua em uma barreira capilar construída com RSU PTMB, em detrimento ao bidimensional.

O controle da taxa de infiltração de água em uma barreira capilar é muito importante na implementação de um sistema de barreira capilar na cobertura de aterros.

Aquela desenvolvida neste estudo é uma opção viável para ser usada em um aterro sanitário, devido à possibilidade de controle da infiltração da água e ao fato de usar o RSU tratado e não o solo para construir os sistemas de cobertura em um aterro sanitário, o que pode acarretar em economia financeira para a obra. Além disso, o uso do RSU PTMB pode representar um ganho significativo no volume disponível para armazenamento de RSU no aterro sanitário.

\section{Referências}

CABRAL, A.; EL-GHABI, B.; PARENT, S.É.; MARINEAU, L. (2007) Design and Performance of a Double Capillary Barrier Cover Placed in a MSW Landfill in Quebec, Canada. In: Proceedings Sardinia 2007, Eleventh International Waste Management and Landfill Symposium, CISA publisher, S. Margherita di Pula, Cagliari, Italy; 1-5 October.

KHIRE, M.V.; BENSON, C.H.; BOSSCHER, P.J. (2000) Capillary Barriers: Design Variables and Water Balance. Journal of Geotechnical and Geoenvironmental Engineering, v. 126, n. 8, p. 695-708.

KRISDANI, H.; RAHARDJO, H.; LEONG, E. (2005) Behaviour of Capillary Barrier System Constructed using Residual Soil. Austin, Texas, United States: Geotechnical Special Publications - GeoFrontiers.

MÜNNICH, K.; BAUER, J.; FRICKE, K. (2009) Laboratory Tests to Determine Water Balance Parameters of MBT Material. In: Third International Workshop "Hydro-Physico-Mechanics of Landfills", Braunschweig, Germany, Paper 22, 10 p.

ROCHA, E.F.; AZEVEDO, R.F. (2008) Determinação da condutividade hidráulica e capacidade de campo de resíduos sólidos urbanos. In: XVI Congresso Brasileiro de Mecânica dos Solos e Engenharia Geotécnica COBRAMSEG, Búzios, Rio de Janeiro, 23 a 26 de agosto.
STAUB, M.; GALIETTI, B.; OXARANGO, L.; KHIRE, M.V.; GOURC, J.P. (2009) Porosity and Hydraulic Conductivity of MSW Using Laboratory Scale Tests. In: Third International Workshop "Hydro-Physico-Mechanics of Landfills", Braunschweig, Germany, 10-13 March, Paper 21, 10 p.

SUZUKI, M.; IMAI, J.; SAITA, Y.; NISHIGAKI, M. (2005) Substantiations and Analysis for the Capping With the Capillary Barriers. In: Proceedings Sardinia 2005, Tenth International Waste Management and Landfill Symposium, S. Margherita di Pula, Cagliari, Italy; 3-7 October.

VIEIRA, A.M. (2005) Estudo de Barreiras Capilares Comocobertura Final de Aterro de Resíduos. Tese (Doutorado), Escola Politécnica da Universidade de São Paulo, São Paulo, Brasil, 265 p.

WEIB, J.; WITZSCHE, A. (2005) Results of the Efficiency of the Capillary Barrier System at the Landfill Grix Offenbach-Germany. In: Proceedings Sardinia 2005, Tenth International Waste Management and Landfill Symposium, S. Margherita di Pula, Cagliari, Italy; 3-7 October.

ZARDAVA, K.; POWRIE, W.; WHITE, J. (2009) The Determination of the Moisture Retention Characteristics of Waste Materials Using Vertical Drainage Experiments. In: Third International Workshop "Hydro-Physico-Mechanics of Landfills", Braunschweig, Germany, 10-13 March, Paper 23, 10 p. 